\title{
Vibration analysis of a bucket wheel excavator boom using rayleigh's damping model
}

\author{
Florin Dumitru Popescu, Sorin Mihai Radu \\ University of Petrosani, Romania \\ Krzysztof Kotwica
}

AGH University of Science and Technology, Poland

Andrei Andraș, Ildiko Kertesz (Brînaș), Stela Dinescu

University of Petroșani, Romania

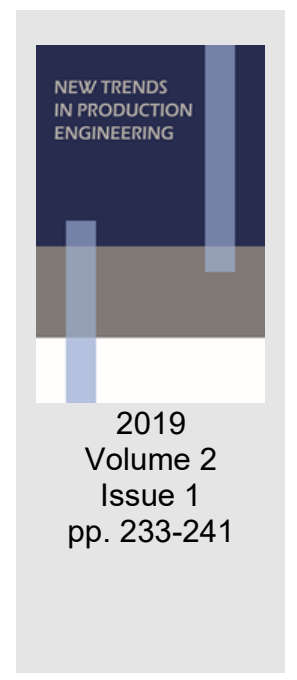

Date of submission to the Editor: 05/2019

Date of acceptance by the Editor: 07/2019

\section{INTRODUCTION}

According to (Nan, 2007), the bucket wheel excavator (BWE) is a continuous digging equipment used to dislocate the material, using teeth-equipped buckets mounted on a turning wheel, and at the same time to transport this excavated material, using conveyor belts installed on its boom, to the main conveyor. The operating tool is the bucket wheel (or rotor), which performs a rotating movement in the vertical plane (xz) and at the same time, together with the boom, a slewing movement on the horizontal plane (xy) and ahoisting movement on the vertical plane (xz) (Figure 1).

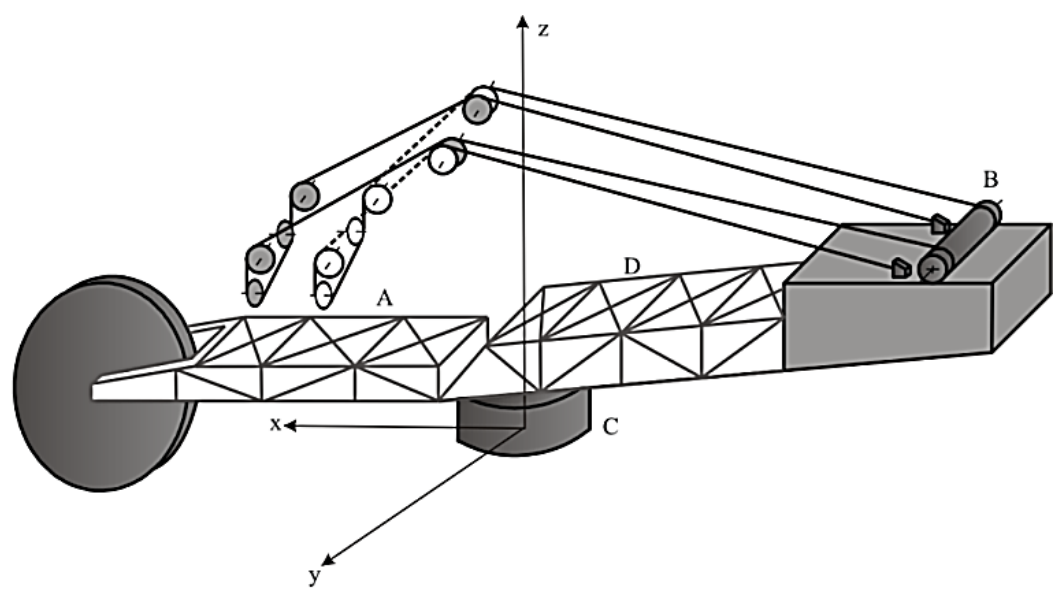

Fig.1 Bucket wheel excavator schematics

A - boom of the bucket wheel, B - hoisting mechanism, C-pivoting mechanism, $\mathrm{D}$ - boom of the counterweight

The model developed for this research and the simulations done in SOLIDWORKS ${ }^{\circ}$, is based on the ERc 1400-30/7 (ROMINEX, 2007) type BWE. The developed model is suitable for the analysis of the deformations of the BWE boom, as it is subjected to the action of the excavation forces. 
Figure 2 shows the ERc 1400-30/7 bucket wheel and thekinematic chain of it drive mechanism (ROMINEX, 2007) made up of the following elements:

- 1 - electric drive motor;

- 2 - elastic coupling;

- 3 -gearbox;

- 4 - transmission shaft;

- 5 - bucket wheel reduction gear;

- 6 - the bucket wheel (rotor):

o 6.1 - cutting buckets;

o 6.2 - cutting-loading buckets;

- 7 - bucket wheel axle.

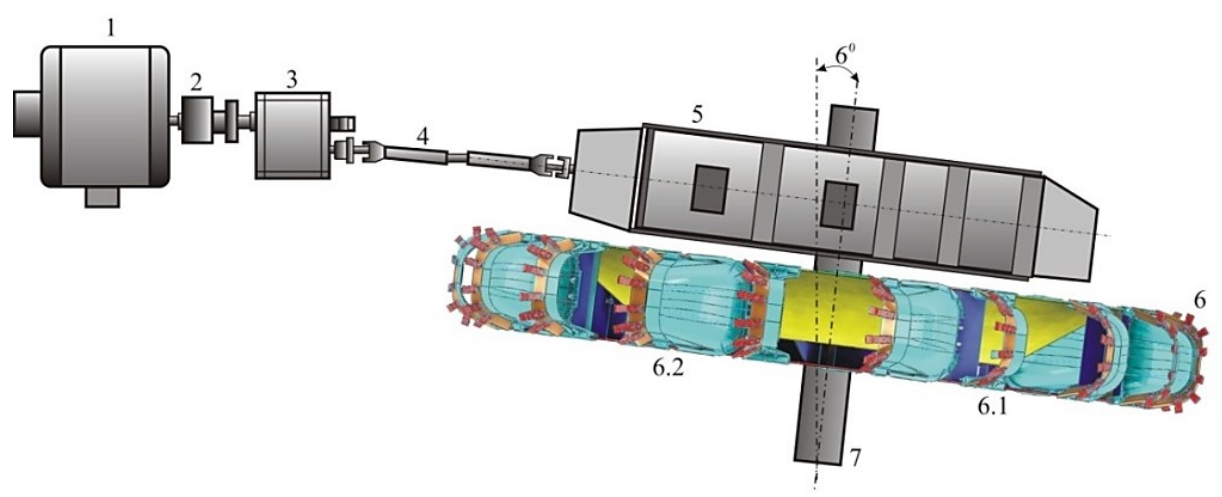

Fig. 2 Kinematic chain of the bucket wheel drive mechanism

\section{CREATING THE BUCKET WHEEL BOOM MODEL}

Based on the constructive characteristics (ROMINEX, 2007) of the ERc 1400$30 / 7$ type BWE, a model was build using SOLIDWORKS® in order to study the behavior of the bucket wheel boom during excavation.

The bucket wheel is the main element that produces loads of the boom during the excavation process. A simplified model was developed, with the same geometric dimensions as the real bucket wheel. The static load that the bucket wheel exerts on the boom is due to its weight. In order to obtain the same mass of the model as that of the real bucket wheel, a density of the material of $\delta=373$ $\mathrm{kg} / \mathrm{m}^{3}$.

According to (Vîlceanu, 2018), the ERc 1400-30/7 bucket wheel excavator boom is a spatial, load-bearing truss type structure that can be divided into three sections (Figure 3):

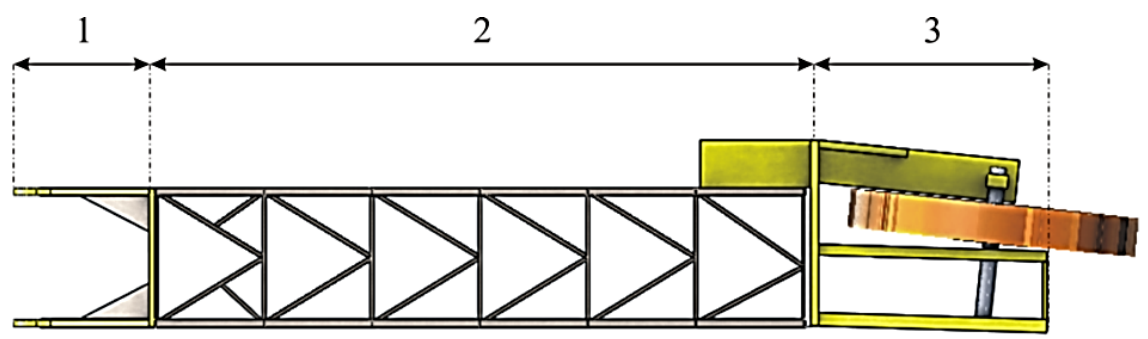

Fig. 3 Cutting forces diagram: a). for cutter - loader buckets, b). for cutter buckets

1. A joint section between the boom and the rest of the structure - which allows both a verticalhoisting movement and a horizontal slewing movement; 
2. An intermediate section - on which the conveyor belt for the discharge of the excavated material is mounted;

3. A bucket wheel support section - on which the bucket wheel drive mechanisms, as well as the boom hoist cables attachments are mounted.

Figure 4 details the intermediate section described above. This section is constructed of the following parts:

- The upper chord consisting of:

o Load bearing longitudinal beams (red);

o Struts (green);

o Wind bracings (yellow);

- The bottom chord consisting of:

o Load bearing longitudinal beams (red);

o Struts (green);

o Wind bracings (yellow);

- Left girder consisting of:

o Struts (gray);

o Wind bracings (blue);

- Right girder consisting of:

o Struts (gray);

o Wind bracings (blue);

Fig. 4 The intermediate section of the bucket wheel boom

Constructively, this section is a truss structure of beams positioned horizontally or inclined, subjected mostly to bending stresses. Truss structures or lattice beams are made up of interconnected beams, and structurally there are the following components (Figure 5):

- Nodes (1, 2, 3, 4, 5, 6, 7, 8);

- Chords:

o top chord made up of longitudinal beams: (1-2), (2-3), (3-4), (4-5);

o bottom chord made up of longitudinal beams: (1-6), (6-7), (7-8), (8-5);

- Girders:

o struts: (2-6), (3-7), (4-8);

o braces orwind bracings: (1-6), (6-3), (3-8), (8-5);

- External joints of the truss: (1) and (5). 


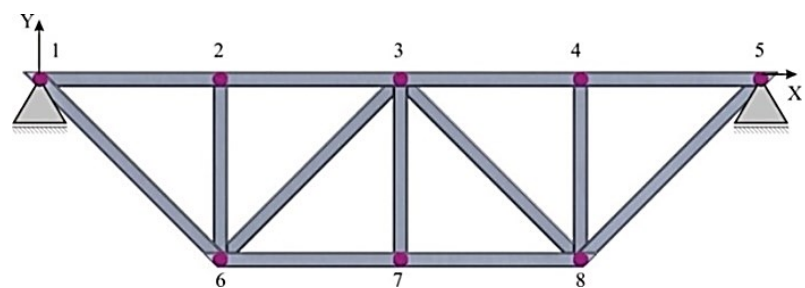

Fig. 5. Truss structure

There are several forces acting on the buckets mounted on the bucket wheel: the cutting force, the advance force, the lateral force and the force corresponding to the weight of the lifted material. Of these, two have a regular character:

- the cutting forces, tangent to the circle described by the cutting edges and acting on both the cutter-loader and the cutter buckets (Figure 6);

- the forces corresponding to the weight of the material, acting as soon as a particular cutter-loader bucket enters the excavation process until the excavated material in this bucket is discharged to the conveyor. (Figure 6).

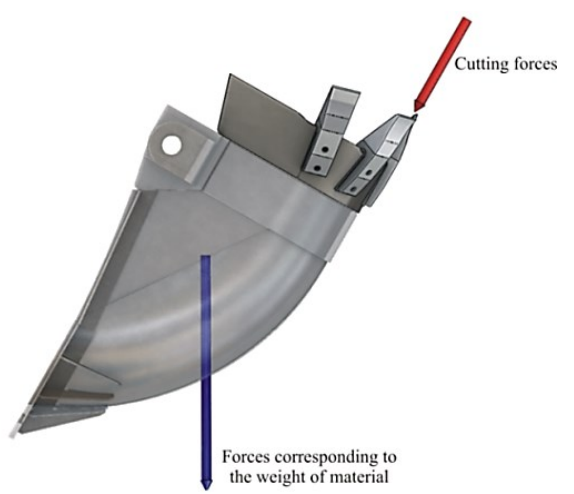

Fig. 6 Forces acting on a cutter-loader bucket

Figure 7 shows the variation of the resultant force during the excavation process according to (Radu et al., 2018).

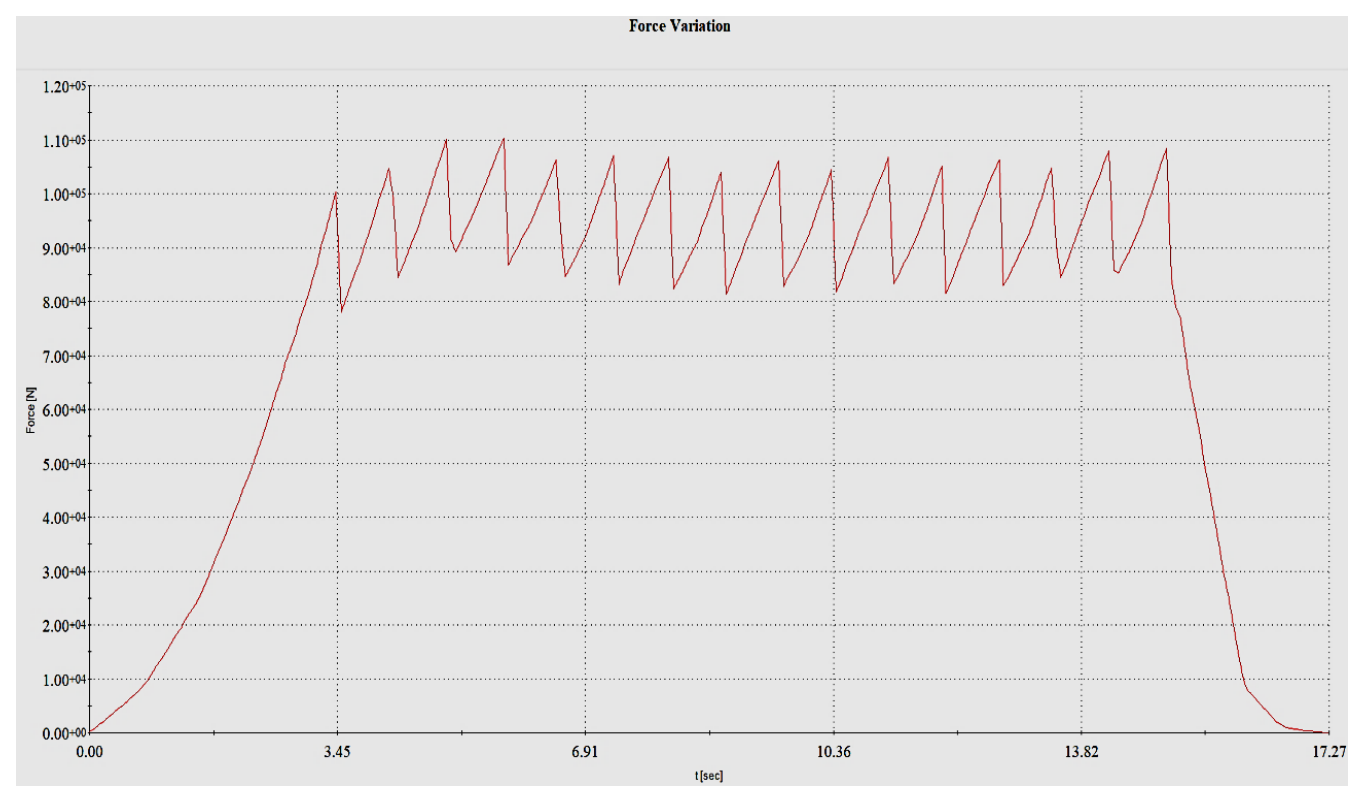

Fig. 7 Variation of the resultant force during excavation 
The amplitude of the force depends on the hardness and density of the excavated rock. The frequency is imposed by the rotation speed of the bucket wheel (in the case of the studied BWE equal to $4.33 \mathrm{rot} / \mathrm{min}$ ) and the number of buckets mounted on it ( 9 cutter and 9 cutter-loader buckets for this BWE). The chart captures a timeframe in which the bucket wheel performs more than one complete rotation.

Implementation of the force variation diagram using SOLIDWORKS ${ }^{\circ}$, in order to determine the deformation of the boom during the excavation process, is shown in Figure 8 (Radu et al., 2018).

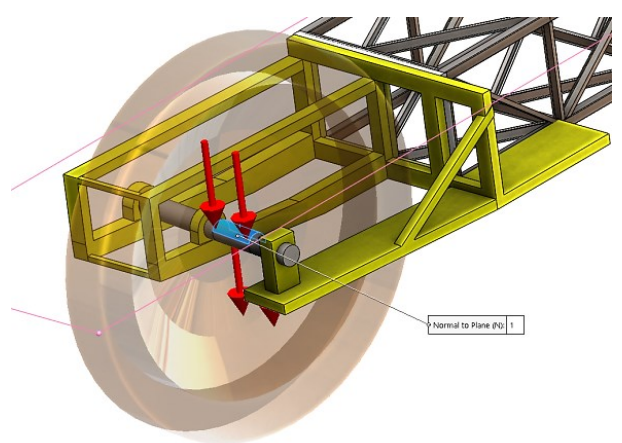

Fig. 8 Force implementation in the model

The elements of the kinematic chain of the excavator bucket wheel drive system are modeled by a uniformly distributed mass of 29000 kilograms, as shown in Figure 9.

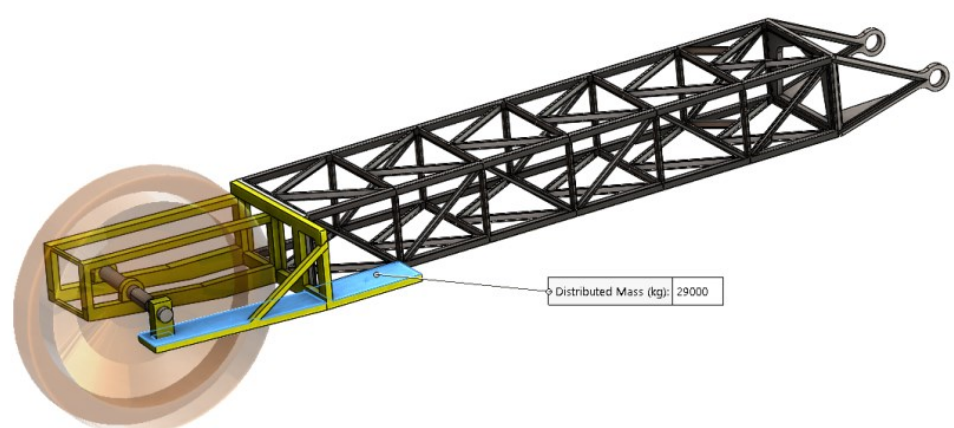

Fig. 9 Modeling of the kinematic chain elements using a uniformly distributed mass

The conveyor belt mounted inside the boom was modeled using a remote mass of 25000 kilograms, according to the technical specifications of the BWE (Figure 10).

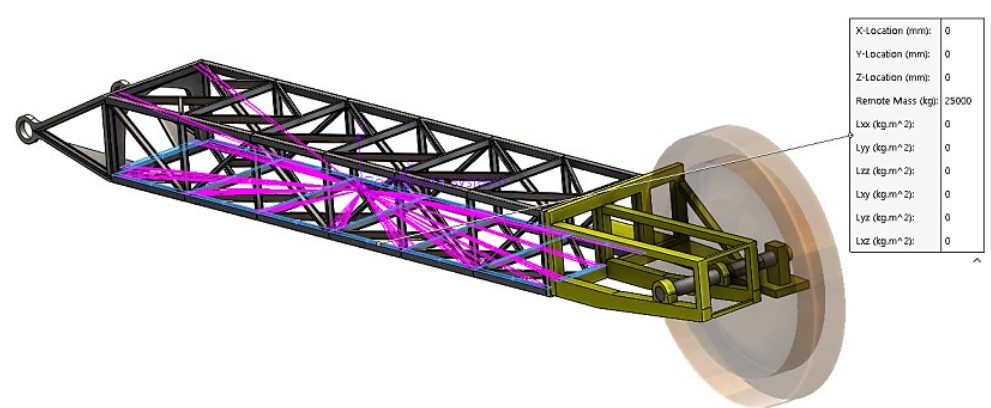

Fig. 10 Modeling of the conveyor belt 
The 10 cables of WS $\$ 40-6 \times 36$ zinc coated-S/Z type that are used for supporting and hoisting of the boom, are modeled as two springs subjected to elongation (Figure 11), with an equivalent elasticity constant of $35.000 .000 \mathrm{~N} / \mathrm{m}$ per cable.

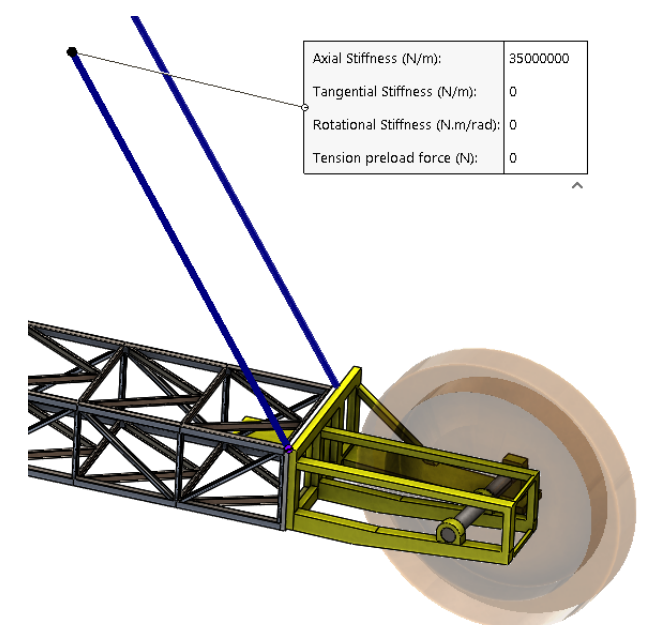

Fig. 11 Modeling of the support and hoisting cables of the BWE boom

\section{THE DYNAMIC ANALYSIS OF THE BOOM DEFORMATIONS USING RAYLEIGH DAMPING}

In dynamic analysis, damping can be defined as of Rayleigh type for which the damping matrix is dependent on the mass and stiffness matrices (Kurowski, 2016). Rayleigh's damping is defined by two damping coefficients, $\alpha$ and $\beta$. Alpha is known as a viscous damping component also known as mass damping, and it characterizes damping of low frequencies. Beta is a hysteresis damping component also known as solid or stiffness damping, and it characterizes damping of high frequencies.

The expression that characterizes the two damping coefficient is:

$$
[C]=\alpha \cdot[M]+\beta \cdot[K]
$$

where:

$[M]$ - is the mass matrix;

$[C]-$ is the damping matrix;

$[K]-$ is the stiffness matrix.

In relation to the damping ratio $\xi$, the two damping coefficients $\alpha$ and $\beta$ are defined as:

$$
\frac{\alpha}{2 \cdot \omega}+\frac{\beta \cdot \omega}{2}=\xi
$$

where:

$\xi-$ is the damping ratio.

The variation of the damping coefficients alpha and beta with pulse frequency is shown in Figure 12. 


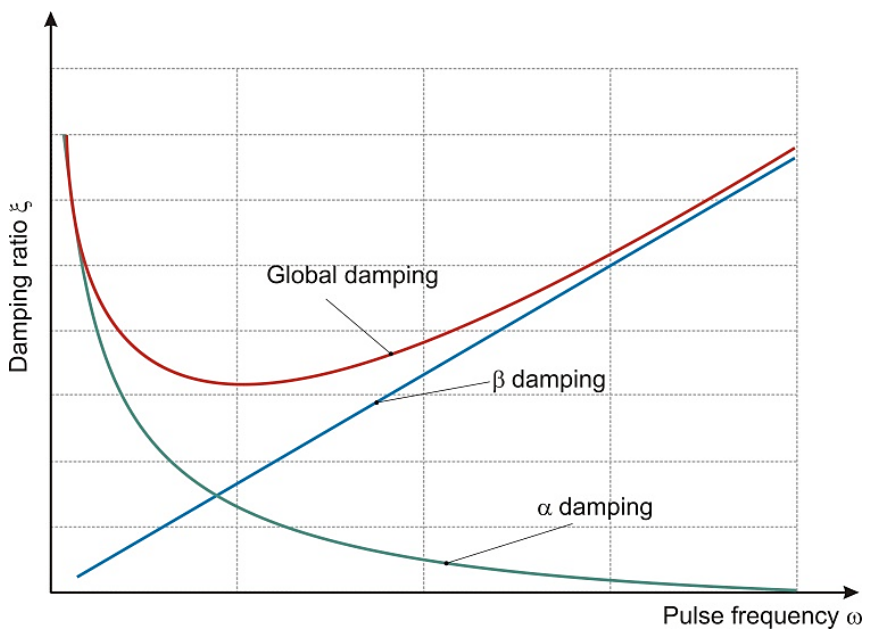

Fig. 12 Damping ratio, a and b damping coefficients variation with pulse frequency

In order to calculate the two damping coefficients $\alpha$ and $\beta$, the frequencies corresponding to two vibration modes of the dynamic linear analysis will be considered. For mode 1 the damping ratio is $2 \%$ (corresponding to a pulse frequency of $11.791 \mathrm{rd} / \mathrm{s}$ ) and for mode 10 the damping ratio is $10 \%$ (corresponding to a pulse frequency of $110.002 \mathrm{rd} / \mathrm{s}$ ). The global damping ratio variable with frequency was considered according to (Sun et al.,1985).

Table 1 Displacement of the bucket wheel jib obtained in simulations

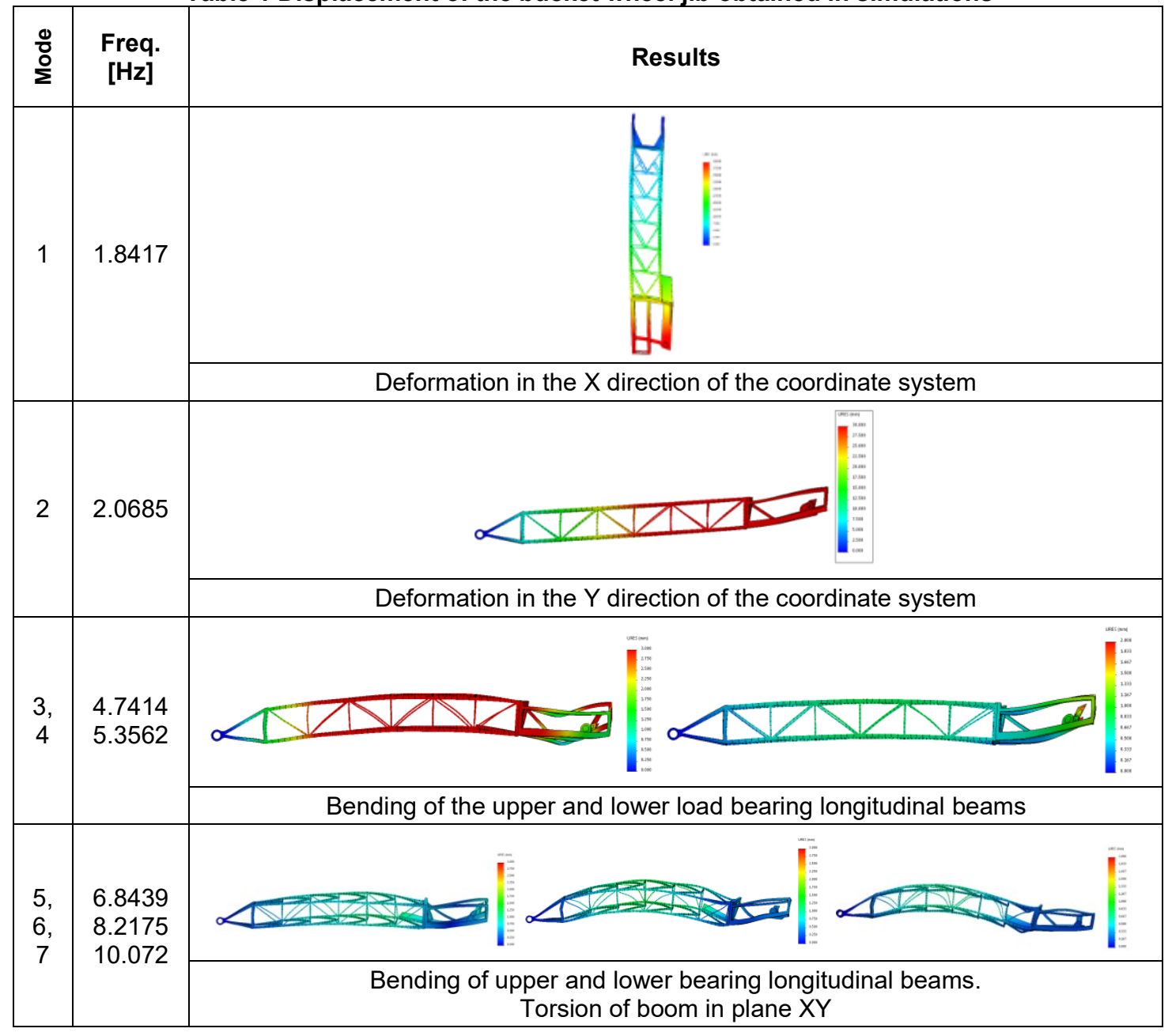




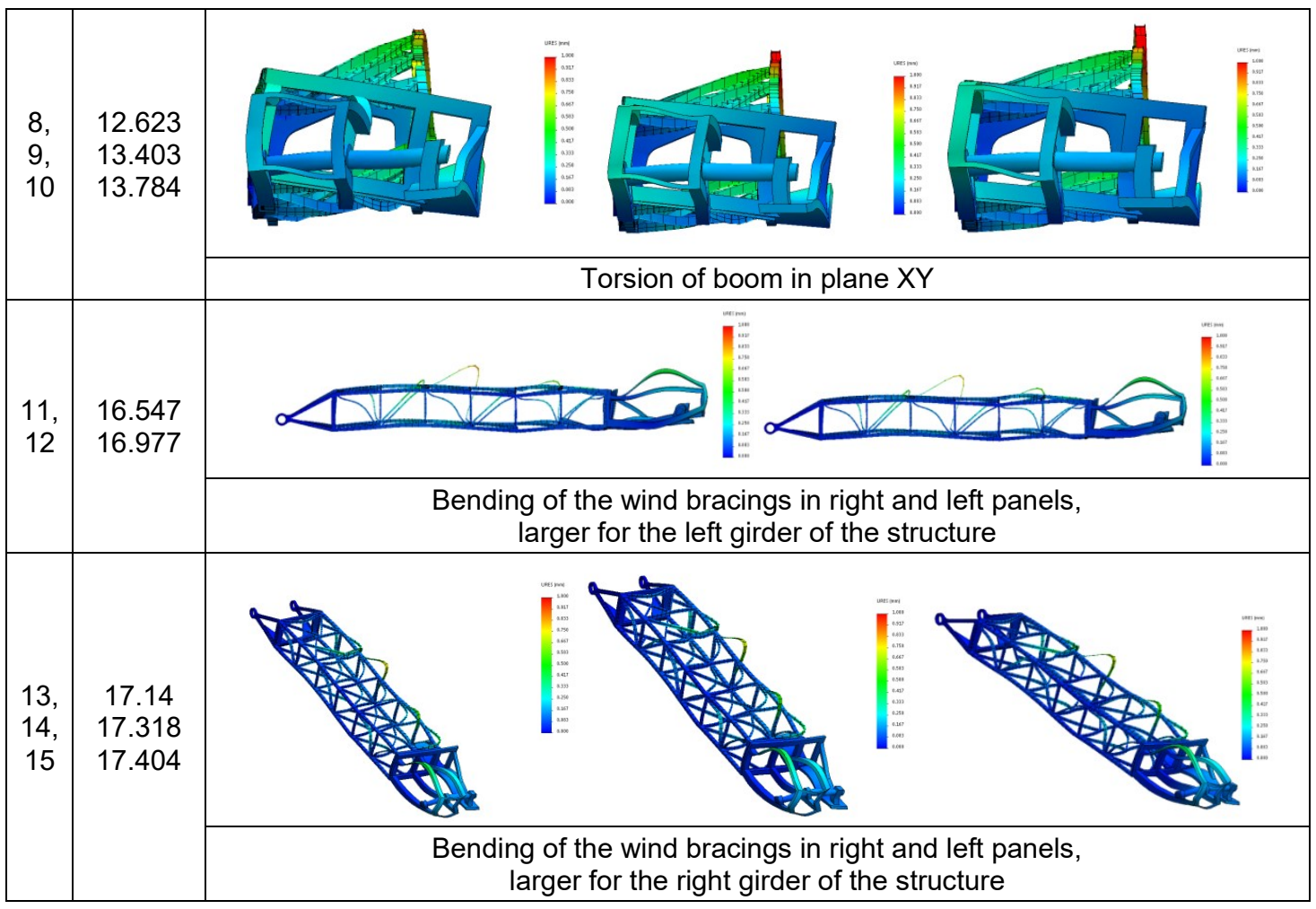

For these two modes, the following linear equations system has to be solved:

$$
\left\{\begin{array}{l}
\frac{\alpha}{2 \cdot \omega_{1}}+\frac{\beta \cdot \omega_{1}}{2}=\xi_{2 \%} \\
\frac{\alpha}{2 \cdot \omega_{10}}+\frac{\beta \cdot \omega_{10}}{2}=\xi_{10 \%}
\end{array}\right.
$$

where:

$\omega_{1}$ - is the pulse frequency of the first resonance frequency;

$\omega_{10}$ - is the pulse frequency of the $10^{\text {th }}$ resonance frequency;

$\xi_{2 \%}, \xi_{10 \%}$ - are the corresponding global damping factors.

By solving the system of equations (3) the values of the two damping coefficients are $\alpha=0.221$ and $\beta=1.8 .10^{-3}$.

Table 1 shows the resultant displacements of the bucket wheel boom obtained after the simulations in SOLIDWORKS $®$ for the first 15 vibration modes.

\section{CONCLUSIONS}

The virtual model of the ERc 1400-30/7 BWE boomcan be used to highlight the deformations during the excavation process. The study is based on the dynamic analysis of the time response of the bucket wheel boom, considering a Rayleigh type damping. The results show which structural element have the highest deformation for each modal frequency. Only the first 15 modal frequencies were considered, covering a frequency range between 1.8417 and $17.404 \mathrm{~Hz}$, because the cumulative masses participation factorfor $X$ and $Y$ directions, starting with Mode 11 , exceed $80 \%$. These directions are more likely to have vibration induced stresses due to the excavation process, but also due to the constructive structure of the BWE boom. Thus, for the first two modal 
frequencies, there are deformations in the direction $X$,and respectively $Y$ of the coordinate system. Modes 3 and 4 produce bending of the upper and lower bearing beams. The bending of the upper and lower bearing beams and the torsion of the boom in the XY plane are critical for modes 5, 6 and 7. Modes 8, 9 and 10 produce torsion of the boom in the XY plane. Modes 11 to 15 produce bending of the wind bracings in the lateral panels. The results obtained confirm the statement of (Kurowski, 2015), that at high frequencies there is a tendency to maximize elastic energy and minimize kinetic energy, while for low frequencies the tendency is to minimize the elastic energy and maximize the kinetic energy.

\title{
REFERENCES
}

Nan, M.S. (2007). Parametrii procesului de excavare la excavatoar ele cu rotor. Petroşani: Universitas.

ROMINEX S.A. (2007). Excavatorul cu roatăportcupe ERc 1400 - 30/7 modernizat, instrucţiuni de exploatare, întreţinereşireparaţii. Timişoara.

Vîlceanu, V. F. (2018). Studiulduratei de viaţăpentruutilajele de extragereşidepunereîndepozite, utilizateîncarierele din bazinulOlteniei, PhD. University of Petroșani.

Radu, S.M., Popescu, F.D., Andraș, A., Kertesz, (Brînaş) I. (2018). Simulation and modeling of the forces acting on the rotor shaft of BWEs, in order to improve the quality of the cutting process. Annals of the University of Petroşani, Mechanical Engineering, 20, pp. 63-72.

Kurowski, P.M. (2016). Vibration Analysis with SOLIDWORKS $尺$ Simulation. Mission: SDC Publications.

C. T. Sun, J. N. Juang (1985), - Modeling Global Structural Damping in Trusses Using Simple Continuum Models, AIAA JOURNAL, VOL. 24, NO. 1, pp. 144-150;

Kurowski, P. M. (2015). Engineering Analysis with SOLIDWORKS $®$ Simulation. Mission: SDC Publications.

\begin{abstract}
.
For the ERc 1400-30/7 type bucket wheel excavator (BWE) used in various Romanian open pit mines, a virtual model of the boom was constructed in SolidWorks. On this model, the variable in time forces acting during the excavation process were simulated, and the time history analysis (time response) was performed. This dynamic time response analysis was performed for excavation of homogenous material only, considering the damping as being of Rayleigh's type, where the damping matrix is a linear combination of the mass and stiffness matrices. Based on the conducted analysis, the displacements of the boom during excavation were observed.
\end{abstract}

Keywords: Bucket wheel excavator, damping, frequency response, modal analysis, resonance 